\title{
Influência do tipo de corte na qualidade de abobrinha 'Menina Brasilei- ra' minimamente processada
}

\author{
Brígida M Vilas Boas ${ }^{1,2}$; Elisângela Elena Nunes ${ }^{1,2}$; Eduardo Valério de B Vilas Boas ${ }^{1,3}$; Andréa Luiza RP \\ Xisto ${ }^{1,3}$ \\ ${ }^{1}$ UFLA- Dep ${ }^{\text {to }}$ Ciência dos Alimentos-DCA, C. Postal 37, 37200-000 Lavras-MG; ${ }^{2}$ Bolsista CAPES; ${ }^{3}$ Bolsista CNPq; E-mail: \\ bmvboas@hotmail.com
}

\begin{abstract}
RESUMO
O objetivo deste trabalho foi avaliar o efeito do tipo de corte na manutenção da qualidade de abobrinhas 'Menina Brasileira' minimamente processadas armazenadas sob refrigeração. As abobrinhas foram fatiadas ou raladas, sendo sanificadas com solução de hipoclorito de sódio $50 \mathrm{mg} \mathrm{L}^{-1}$ por 10 minutos. Estas foram acondicionadas em bandejas de polipropileno envoltas com filme de PVC $\left(0,020 \mathrm{~mm}\right.$ de espessura), e armazenadas em câmara fria $\left(6^{\circ} \mathrm{C}\right.$ e $95 \%$ UR) por 12 dias. As seguintes variáveis foram avaliadas: perda de massa, $\mathrm{pH}$, sólidos solúveis (SS), valores $\mathrm{L}^{*}, \mathrm{C}^{*} \mathrm{e} \mathrm{h}^{\circ}$, aparência e cor. $\mathrm{O}$ experimento foi conduzido em delineamento inteiramente casualizado em esquema fatorial (2x5), sendo dois tipos de corte (fatiada e ralada) e cinco tempos de armazenamento (0, 3, 6, 9 e 12 dias). A perda de massa foi pequena, atingindo valores máximos de $1,5 \%$ para a abobrinha ralada. Os valores de $\mathrm{pH}$ foram menores a partir do $6^{\circ}$ dia nas abobrinhas raladas quando comparadas às fatiadas. Após o $3^{\circ}$ dia de armazenamento, as abobrinhas raladas apresentaram menores valores de SS em relação às abobrinhas fatiadas. Maiores valores $L^{*}$ foram encontrados nas abobrinhas fatiadas, observando-se um acréscimo ao longo do armazenamento. Abobrinha fatiada apresentou menores perdas de coloração, baseado nos valores $\mathrm{h}^{\circ}$ e $\mathrm{C}^{*}$ e melhor aceitabilidade quando avaliada sensorialmente em relação à ralada, com decréscimos nas notas com o armazenamento. O tipo de corte influencia a vida de prateleira de abobrinha minimamente processada sendo que as formas fatiada e ralada mantêm a aparência e as características físico-químicas até o $12^{\circ}$ dia de armazenamento.
\end{abstract}

Palavras-chave: Cucurbita moschata, armazenamento, refrigeração.

\begin{abstract}
Influence of cut type on quality of $\mathrm{cv}$. 'Menina Brasileira' summer squash fresh-cut
\end{abstract}

The goal of this work was to evaluate the effect of the type of cut the on maintenance quality of fresh-cut 'Menina Brasileira' summer squash stored under refrigeration. Summer squashes were sliced or grated and sanitized with sodium hypochloride solution at $50 \mathrm{mg} \mathrm{L}^{-1}$ for 10 minutes. They were placed in polypropylene packages covered with PVC film $(0.020 \mathrm{~mm})$, and stored in cold chamber $\left(6^{\circ} \mathrm{C}\right.$ and $\left.95 \% \mathrm{RH}\right)$ for 12 days. The following variables were evaluated: Fresh mass loss, $\mathrm{pH}$, soluble solids (SS), L*, $\mathrm{C}^{*}$ and $\mathrm{h}^{\circ}$ values, appearance and color. The experiment was carried out in completely random design in factorial scheme $(2 \times 5)$, with two types of cut (sliced e grated) and five times of storage (0, 3, 6, 9 and 12 days). The fresh mass loss was low, attaining maximal values of $1.5 \%$ in grated summer squash. The values of $\mathrm{pH}$ in grated summer squashes were lower than in sliced summer squashes from $6^{\text {th }}$ day. Grated summer squashes presented lower SS content than sliced summer squashes, after $3^{\text {rd }}$ day of storage. Higher $L^{*}$ values were found in sliced summer squashes and an increase in that variable was observed during the storage. Sliced summer squash presented lower color losses, based to $\mathrm{h}^{\circ}$ and $\mathrm{C}^{*}$ values, and better sensorial acceptability in relation to grated one, with reduction in their scores over the storage period. It was the cut type wich influences the shelflife of sliced and grated summer squashes, keeping their appearance and physical-chemical characteristics until the $12^{\text {th }}$ day of storage.

Keywords: Cucurbita moschata, storage, refrigeration.

\section{(Recebido para publicação em 25 de abril de 2005; aceito em 26 de abril de 2006)}

$\mathrm{D}$ entre as culturas oleráceas tipicamente tropicais, as cucurbitáceas ocupam um lugar de destaque, sendo seus produtos de grande aceitação popular. A espécie Cucurbita moschata (abóbora) tem como centro de origem a região central do México (Filgueira, 2000). Há um grupo de abóboras colhido como abobrinha verde, que é mais bem aceito que a abobrinha-italiana em muitos mercados interioranos. Um bom exemplo é a tradicional cultivar Menina Brasileira, cujos frutos são cilíndricos, medindo cerca de $25 \mathrm{~cm}$ de comprimento, e apresentam pescoço. Apesar da grande aceitação do fruto 'in natura', surge uma nova possibilidade de comercialização desses frutos, que é na forma de produtos minimamente processados.

Segundo o IFPA (2004), produtos minimamente processados são frutos e hortaliças que sofreram alterações físicas a partir de sua forma original, mantendo o seu frescor, sem perder a qualidade nutricional e sensorial. As etapas do processamento mínimo constituem de seleção, lavagem, descascamento e corte, resultando num produto $100 \%$ aproveitável. Esses produtos terão que ter vida de prateleira suficiente para garantir um bom período de comercialização e serem seguros aos consumidores.
Os produtos minimamente processados são altamente perecíveis devido à exposição de seus tecidos internos, causado pelo descascamento e corte. Reações químicas responsáveis pelas modificações da qualidade sensorial (cor, sabor, aroma e textura), bem como nutricional, ocorrem em decorrência do dano físico ou ferimento provocado pelo processamento mínimo. Quanto maior o grau de processamento, mais intensas são as respostas aos ferimentos (Chitarra, 2001; Cantwell \& Suslow, 2002). Diversos procedimentos têm sido utilizados no controle de alterações fisiológicas indesejáveis e que afetam adversamente a qualidade dos produtos 
Tabela 1. Valores médios de perda de massa, $\mathrm{pH}$, sólidos solúveis e ângulo de cor $\left(\mathrm{h}^{\circ}\right)$ de abobrinhas minimamente processadas e armazenadas sob refrigeração $\left(6 \pm 1,5^{\circ} \mathrm{C}\right.$ e $95 \%$ UR) por 12 dias. Lavras, UFLA, 2004.

\begin{tabular}{|c|c|c|c|c|c|}
\hline \multirow{2}{*}{$\begin{array}{l}\text { Tipos de } \\
\text { corte }\end{array}$} & \multicolumn{5}{|c|}{ Armazenamento (dias) } \\
\hline & 0 & 3 & 6 & 9 & 12 \\
\hline & \multicolumn{5}{|c|}{ Perda de massa (\%) } \\
\hline Fatiada & 0 & $0,13 a$ & $0,36 \mathrm{a}$ & $0,48 \mathrm{~b}$ & $0,67 b$ \\
\hline \multirow[t]{2}{*}{ Ralada } & 0 & $0,17 \mathrm{a}$ & $0,46 \mathrm{a}$ & $0,81 \mathrm{a}$ & $1,31 \mathrm{a}$ \\
\hline & \multicolumn{5}{|c|}{$\mathrm{pH}$} \\
\hline Fatiada & $6,48 \mathrm{a}$ & 6,49 a & $6,77 \mathrm{a}$ & $6,51 \mathrm{a}$ & $6,73 \mathrm{a}$ \\
\hline \multirow[t]{2}{*}{$\underline{\text { Ralada }}$} & $6,46 \mathrm{a}$ & $6,51 \mathrm{a}$ & $6,33 \mathrm{~b}$ & $5,78 \mathrm{~b}$ & $6,12 \mathrm{~b}$ \\
\hline & \multicolumn{5}{|c|}{ Sólidos solúveis ( $\left.{ }^{\circ} \mathrm{Brix}\right)$} \\
\hline Fatiada & 2,93 a & $3,30 \mathrm{a}$ & 4,07 a & 3,07 a & $3,17 \mathrm{a}$ \\
\hline Ralada & $2,67 \mathrm{a}$ & $2,17 \mathrm{~b}$ & $2,67 \mathrm{~b}$ & $1,73 \mathrm{~b}$ & $1,67 \mathrm{~b}$ \\
\hline \multirow{3}{*}{$\begin{array}{l}\text { Tipos de } \\
\text { corte }\end{array}$} & \multicolumn{5}{|c|}{ Tempos de armazenamento (dias) } \\
\hline & 0 & 3 & 6 & 9 & 12 \\
\hline & \multicolumn{5}{|c|}{ Ângulo Hue } \\
\hline Fatiada & $97,04 \mathrm{~b}$ & 94,78 b & $94,60 \mathrm{~b}$ & $93,85 b$ & $93,45 \mathrm{~b}$ \\
\hline Ralada & $106,78 a$ & $104,49 a$ & $104,87 a$ & $99,49 a$ & $98,28 a$ \\
\hline
\end{tabular}

Médias seguidas de mesma letra na coluna não diferem entre si, pelo teste de Tukey a $5 \%$.

minimamente processados. Seleção de cultivares, refrigeração adequada, controle da umidade e uso de atmosfera modificada têm sido empregados com sucesso para preservar a qualidade dos produtos e estender sua vida de prateleira.

O processamento mínimo inclui cortes e outros estresses mecânicos, que aceleram o metabolismo da hortaliça, levando à sua rápida deterioração. Desta maneira, o produto obtido tem vida útil menor do que a hortaliça que lhe deu origem e requer condições específicas de acondicionamento e armazenamento, principalmente quanto ao controle da temperatura (Luengo \& Lana, 1997).

O objetivo deste trabalho foi avaliar o efeito do tipo de corte na manutenção da qualidade de abobrinhas 'Menina Brasileira' minimamente processadas e armazenadas sob refrigeração, por 12 dias.

\section{MATERIAL E MÉTODOS}

Utilizou-se abobrinhas da cultivar Menina Brasileira provenientes da CEASA, MG e adquiridas no comércio local de Lavras, MG, sem defeitos aparentes e uniformes quanto ao diâmetro do pescoço ( $5 \mathrm{~cm}$ de diâmetro). Os frutos foram transportadas para o Laboratório defisiologia Pós-Colheita de Frutos e Hortaliças da UFLA, Lavras (MG).
Foram lavadas com detergente neutro a fim de retirar a matéria orgânica e as demais impurezas aderidas ao produto. A etapa seguinte foi a sanificação através da imersão dos frutos em solução de hipoclorito de sódio a $300 \mathrm{mg} . \mathrm{L}^{-1}$ por 15 minutos, seguida de secagem à temperatura ambiente. As abobrinhas foram fatiadas ( $7 \mathrm{~mm}$ de espessura) ou raladas (tiras de $3 \mathrm{~cm}$ de comprimento) manualmente com auxílio de faca inoxidável afiada e ralador inox com orifícios de $0,5 \mathrm{~cm}$ de diâmetro, respectivamente, sendo posteriormente sanificadas com hipoclorito de sódio a $50 \mathrm{mg} \mathrm{L}^{-1}$ por 10 minutos. Em seguida, as abobrinhas fatiadas e as raladas foram escorridas em peneira plástica, por 2 minutos, para a lado. O produto minimamente processado foi acondicionado em bandejas de polipropileno (15,0 $\mathrm{cm}$ x $11,5 \mathrm{~cm} \mathrm{x} \mathrm{4,5}$ $\mathrm{cm})$, envoltas com filme de PVC $(0,020$ $\mathrm{mm}$ de espessura). As bandejas foram armazenadas em câmara fria $\left(6 \pm 1,5^{\circ} \mathrm{C}\right.$ e $95 \%$ UR) por 12 dias e as análises realizadas a cada 3 dias. As seguintes variáveis foram analisadas:

Perda de massa $(\%)$ : calculada pela diferença entre a massa inicial da abobrinha minimamente processada e a obtida em cada tempo de armazenamento, utilizando-se balança semi-analítica Mettler modelo PC 2000. retirada do excesso de líquido acumu-
As avaliações de pH e sólidos solúveis foram feitas em homogenato filtrado em organza, após trituração da polpa em homogeneizador de tecido na proporção 1:5 (polpa:água).

pH: determinado utilizando-se um pHmetro Schott Handylab, segundo a técnica da AOAC (1992).

Sólidos solúveis $\left({ }^{\circ} \mathrm{Brix}\right)$ : utilizando refratômetro digital ATAGO PR-100 (AOAC, 1992).

Valor $\mathbf{L}^{*}, \mathbf{C}^{*}$ e $\mathbf{h}^{\mathbf{0}}$ : utilizou-se colorímetro marca Minolta, modelo CR 300 , realizando-se as leituras dos valores $L^{*}, a^{*}$ e $b^{*}$, sendo estes dois últimos transformados em C* (cromaticidade) e $\mathrm{h}^{\circ}$ (ângulo hue ou ângulo de cor). As leituras foram feitas no centro de cinco fatias de abobrinhas e em cinco pontos, diretamente, na superfície do produto ralado e contido na embalagem.

Aparência e cor: foram avaliadas sensorialmente por 20 pessoas não treinadas, que utilizaram escala hedônica de 5 pontos para dar notas à aparência e à cor dos produtos fatiados e ralados: 1não consumível, 2- limite de consumo, 3- limite de comercialização, 4- bom e 5- excelente.

O experimento foi conduzido em delineamento inteiramente casualizado, com 3 repetições, em esquema fatorial $2 \times 5$, sendo 2 tipos de corte (fatiada e ralada), e 5 tempos de armazenamento $(0 ; 3 ; 6 ; 9$ e 12 dias). As análises estatísticas foram realizadas através de análise de variância, teste de médias e regressão polinomial.

\section{RESULTADOS E DISCUSSÃO}

Houve interação significativa entre os fatores tipo de corte e tempo de armazenamento para a variável perda de massa. A abobrinha ralada apresentou maior porcentagem de perda de massa que a fatiada no nono e décimo segundo dias de armazenamento (Tabela 1). A abobrinha ralada é um produto minimamente processado com maior área de exposição dos tecidos internos e mais propício à perda de exsudatos, o que pode comprometer a aparência (murchamento e enrugamento), a textura (amaciamento e perda de frescor)e 
a qualidade nutricional. Porém, em termos práticos, essa perda de massa foi pequena, não ultrapassando $1,5 \%$ no produto ralado, pois o do filme de PVC utilizado oferece uma barreira contra a saída de vapor de água do interior da embalagem. Vitti et al. (2003) encontraram valores de perda de massa próximos a $0 \%$ em beterrabas minimamente processadas e acondicionadas em bandejas de poliestireno expandido envolvidas com filme de PVC (0,014 mm de espessura) e armazenadas por 10 dias, a $5^{\circ} \mathrm{C}$. Os resultados encontrados no presente trabalho concordam com os de Izumi et al. (1996) que observaram maior perda de massa em cenouras raladas $(3,3 \%)$, quando comparadas com cenouras fatiadas $(1,5 \%)$, durante armazenamento a $5^{\circ} \mathrm{C}$, por 21 dias.

As variáveis $\mathrm{pH}$ e sólidos solúveis (SS) foram influenciadas interativamente pelos fatores, tipo de corte e tempo de armazenamento. Nas abobrinhas raladas, os valores de $\mathrm{pH}$ e $\mathrm{SS}$ foram menores em relação às fatiadas, a partir do sexto e terceiro dias de armazenamento, respectivamente (Tabela 1).

$\mathrm{O}$ ato de ralar é mais estressante para o tecido vegetal que o corte em fatias, pois aumenta a superfície cortada do vegetal e a descompartimentação celular, levando ao maior extravasamento do conteúdo celular. Tal extravasamento, bem como a possível exacerbação do metabolismo provocada pelo estresse, parecem ter promovido a maior redução dos teores de SS nas abobrinhas raladas, visto que o metabolismo promove decréscimos nas reservas energéticas, principalmente dos açúcares livres e dos ácidos orgânicos (Chitarra, 2001).

De acordo com Luengo \& Lana (1997), a utilização de instrumentos de corte bem afiados é importante para a obtenção de produtos com alta qualidade, bem como a direção do corte influencia a vida útil. A durabilidade de pimentão e cenoura cortadas no sentido transversal (rodelas) é maior quando comparada com o corte longitudinal (palito) (Luengo \& Lana, 1997).

As variáveis luminosidade $\left(\mathrm{L}^{*}\right)$ e cromaticidade $\left(\mathrm{C}^{*}\right)$ foram afetadas significativamente pelos fatores tipo de corte e tempo de armazenamento, não

Tabela 2. Valor luminosidade $\left(\mathrm{L}^{*}\right)$, valor de cromaticidade $\left(\mathrm{C}^{*}\right)$ e análise sensorial da aparência e da coloração (notas) de abobrinhas minimamente processadas e armazenadas sob refrigeração $\left(6 \pm 1,5^{\circ} \mathrm{C}\right.$ e 95\% UR) por 12 dias. Lavras, UFLA, 2004.

\begin{tabular}{lcccc}
\hline Tipo de corte & $\mathbf{L}^{*}$ & $\mathbf{C}^{*}$ & Aparência $^{1}$ & Cor $^{1}$ \\
\hline Fatiada & $82,57 \mathrm{a}$ & $32,97 \mathrm{a}$ & $3,71 \mathrm{a}$ & $3,67 \mathrm{a}$ \\
Ralada & $63,80 \mathrm{~b}$ & $24,50 \mathrm{~b}$ & $3,22 \mathrm{~b}$ & $3,24 \mathrm{~b}$ \\
\hline
\end{tabular}

Notas: 1- não consumível, 2- limite de consumo, 3- limite de comercialização, 4- bom e 5excelente.

Obs.: Médias seguidas de mesma letra na coluna não diferem entre si, pelo teste de Tukey a 5\%.

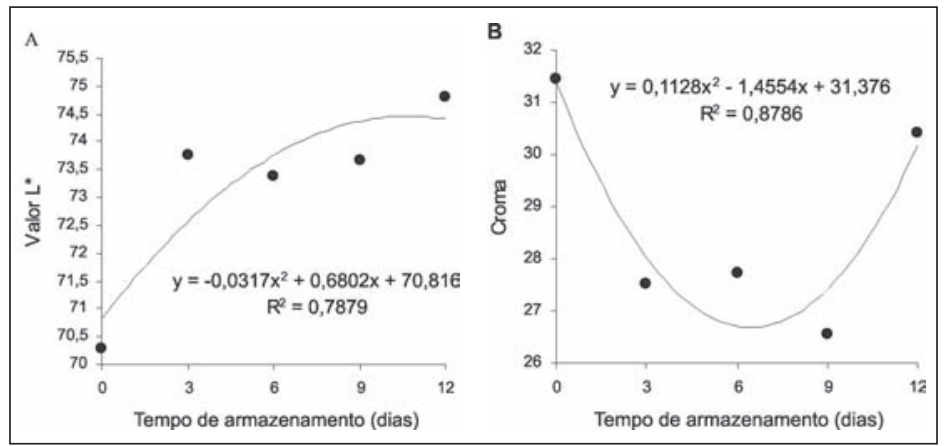

Figura 1. Luminosidade (L*) (A) e cromaticidade (C*) (B) de abobrinhas minimamente processadas e armazenadas sob refrigeração $\left(6 \pm 1,5^{\circ} \mathrm{C}\right.$ e $95 \%$ UR) por 12 dias. Lavras, UFLA, 2004.

havendo interação entre estes fatores. Maiores valores de $\mathrm{L}^{*}$ foram encontrados nas abobrinhas minimamente processadas em fatias (Tabela 2), uma vez que as determinações foram feitas apenas no centro das fatias, sem interferência da casca.

O valor de $\mathrm{C}^{*}$, aumenta, a partir do zero, em função de aumentos nos valores absolutos de a* e b*. A abobrinha fatiada apresentou maior valor de $\mathrm{C}^{*} \mathrm{em}$ relação à ralada, sugerindo uma coloração amarela mais clara, que pode ser reforçada pelo seu maior valor $\mathrm{L}^{*}$ (Tabela 2). Já a abobrinha ralada apresentou coloração esverdeada mais intensa, devido à presença da casca.

De acordo com a Figura 1A, foi observado uma tendência de acréscimo no valor L* ao longo do armazenamento. Isto pode ser devido à desidratação da abobrinha minimamente processada. Pilon (2003) observou um esbranquiçamento em cenoura minimamente processada durante todo período de armazenamento ( 21 dias a $1 \pm 1^{\circ} \mathrm{C}$ ).

As abobrinhas minimamente processadas apresentaram decréscimo nos valores de $\mathrm{C}^{*}$ até o sexto dia, o que impli- ca em uma diminuição na intensidade da cor, observando-se em seguida aumento nestes valores até o final do armazenamento (Figura 1B).

Verificou-se interação significativa entre os fatores tipo de corte e tempo de armazenamento para a variável ângulo de cor $\left(\mathrm{h}^{0}\right)$. Durante todo o período de armazenamento, a abobrinha ralada apresentou maior ângulo de cor $\left(\mathrm{h}^{0}\right)$ (Tabela 1$)$, o que indica a tonalidade de cor mais verde. $\mathrm{Oh}^{0}$ é definido iniciando no eixo $+\mathrm{a}^{*} \mathrm{e}$ é expresso em graus; $0^{0}$ seria $+\mathrm{a}^{*}$, correspondendo ao verde e $270^{\circ}$ seria $-b^{*}$, correspondendo ao azul. Logo, os valores de $\mathrm{h}^{0}$ encontrados neste trabalho sugerem coloração amarelo-esverdeada para as abobrinhas, menos intensamente esverdeado nas abobrinhas fatiadas. Observou-se também que tanto o ângulo de cor da abobrinha fatiada quanto o da ralada reduziram durante o período de armazenamento, uma vez que a perda de coloração foi mais acentuada na abobrinha ralada (Tabela 1).

Houve efeito significativo dos fatores tipo de corte e tempo de armazenamento para as variáveis aparência e cor, isoladamente. A abobrinha fatiada apresentou melhor aceitabilidade quando avaliada sensorialmente, quan- 


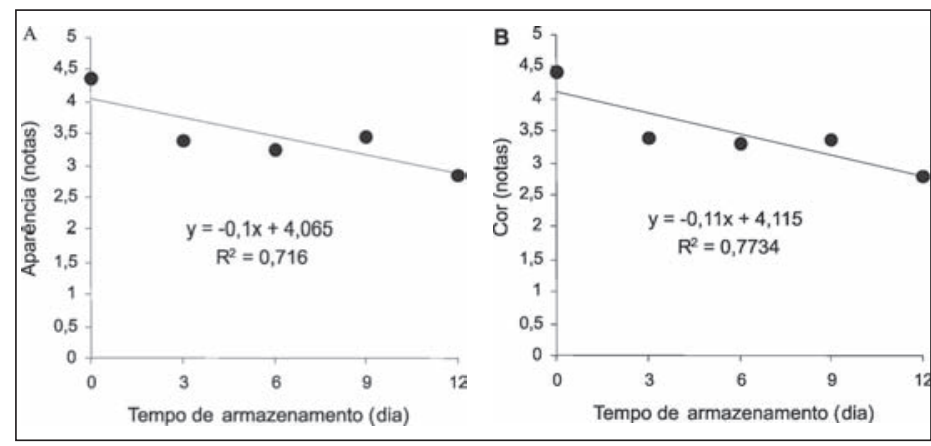

Figura 2. Avaliação sensorial da aparência (A) e da corolação (B) de abobrinhas minimamente processadas e armazenadas sob refrigeração $\left(6 \pm 1,5^{\circ} \mathrm{C}\right.$ e $95 \%$ UR), por 12 dias. Lavras, UFLA, 2004.

${ }^{1}$ Nota 1 não consumível, 2 limite de consumo, 3 limite de comercialização, 4 bom e 5 excelente.

to a aparência e coloração, em relação à ralada (Tabela 2), o que coincide com a avaliação instrumental da coloração, com a abobrinha fatiada apresentando coloração amarelada clara. As notas relativas à aparência e a coloração das abobrinhas minimamente processadas diminuíram durante o período de armazenamento (Figuras $2 \mathrm{~A}$ e $2 \mathrm{~B}$ ).

Após o processamento mínimo, as abobrinhas fatiadas e as raladas receberam notas 4,7, referente ao conceito excelente, do terceiro ao nono dia as notas mantiveram-se em torno de 4,0 (bom) e no décimo segundo dia nota decresceu para 3,0 (limite de comercialização). Logo, a abobrinha minimamente processada, a despeito do tipo de corte, manteve-se aparentemente apta para comercialização até o dé- cimo segundo dia.

Diante dos resultados obtidos neste trabalho pode-se concluir que o tipo de corte influencia a vida de prateleira de abobrinha 'Menina Brasileira' minimamente processada, sendo que as formas fatiada e ralada mantêm a aparência e as características físico-químicas até o décimo segundo dia de armazenamento. A abobrinha fatiada apresenta menores res teores de sólidos solúveis e de $\mathrm{pH}$ em relação à ralada.

\section{AGRADECIMENTOS}

Ao CNPq pelo apoio financeiro concedido para realização deste trabalho. perdas de massa e de coloração e maio-

\section{REFERÊNCIAS}

ASSOCIATION OF OFFICIAL ANALYTICAL CHEMISTRY. 1992. Official methods of analysis of the Association of Official Analytical Chemistry. 12.ed. Washington: A.O.A.C. $1015 \mathrm{p}$

CANTWELL MI; SUSLOW TV. 2002. Postharvest handling systems: fresh-cut fruits and vegetables. In: KADER AA (eds). Postharvest technology of horticultural crops. 3.ed. Davis: California. p. 445-463.

CHITARRA MIF. 2001. Alimentos minimamente processados. Lavras: FAEPE. 93p.

FERREIRA DF. 2000. Análises estatísticas por meio do SISVAR para windows versão 4.0. In: REUNIÃO ANUAL DA REGIÃO BRASILEIRA DA SOCIEDADE INTERNACIONALDE BIOMETRIA. Programa e Resumo. São Carlos: UFSCar. p. 235.

FILGUEIRA FAR. 2000. Novo manual de olericultura: agrotecnologia moderna na produção e comercialização de hortaliças. Viçosa: UFV. 402p.

IFPA. 2004. 15 de novembro. International freshcut produce association: fresh-cut innovations through technology. Disponível em http:// www.fresh-cuts.org

IZUMI H; WATADA AE; KO NP; DOUGLAS W. 1996. Controlled atmosphere storage of carrots slices, sticks and shreds. Postharvest Biology and Technology 9: 165-172.

LUENGO RFA; LANA MM. 1997. Processamento mínimo de hortaliças. Brasília: Embrapa Hortaliças. 3p. (Comunicado Técnico: 2)

PILON L. 2003. Estabelecimento da vida útil de hortaliças minimamente processadas sob atmosfera modificada e refrigeração. Piracicaba: USP-ESALQ. 113p. (Tese mestrado).

VITTI MCD; KLUGE RA; YAMAMOTTO LK; JACOMINO AP. 2003. Comportamento da beterraba minimamente processada em diferentes espessuras de corte. Horticultura Brasileira 21: 623-626. 